\title{
Influence of Welding Temperature and Weathering on Inductive Welded Hybrid Joints Made of Steel and TP-FRPC
}

\author{
Stefan Weidmann ${ }^{1, a^{*}}$ and Peter Mitschang ${ }^{1, b}$ \\ ${ }^{1}$ Institut für Verbundwerkstoffe GmbH, Erwin Schrödinger Straße 58, 67663 Kaiserslautern, \\ Germany \\ astefan.weidmann@ivw.uni-kl.de, ${ }^{b}$ peter.mitschang@ivw.uni-kl.de
}

Keywords: induction welding, lap shear strength, hybrid joining, weathering resistance

\begin{abstract}
Aim of this study is to investigate the influence of welding temperature and weathering on bond strength of induction welded hybrid joints made of steel and thermoplastic fiber reinforced polymer composites (TP-FRPC). The used TP-FRPC are continuous glass fiber reinforced polyamide 6 (PA6), -polypropylene (PP), -polycarbonate (PC) and -polyphenylenesulfide (PPS). The metal sheets are mild steel (1.0338 and 1.0330). The surface pretreatments of the metal sheets are either laser structuring in line pattern, perpendicular to the load direction, or two different types of functional coating adhesives (Köratac HL 400 and Köratac HL 403) currently used in coilcoating processes. First the process parameters were optimized for each material combination by investigating the bond strength at different welding temperatures. In a second step, for each material combination, specimens were welded using the determined welding temperatures with the highest bond strength in order to investigate the influence of weathering on hybrid joints. Therefore the cataplasma test (DIN EN 13523-27: 2009) as well as alternating climatic change (BMW PR 308.2) were used.
\end{abstract}

\section{Introduction}

Joining of composites to metals becomes more popular across all industries due to their potential in lightweight design applications. Especially TP-FRPC are of particular interest for mass production due to the ability of welding as an appropriate joining technology. For hybrid structures efficient joining is required, whereby induction welding is suitable due to the good heating properties of metals by means of induction. In literature, several technologies for hybrid joining are reported and the bond strength is investigated. [1, 2, 3] However, these investigations usually examine the bond strength right after joining. Especially for welding TP-FRPC to metals weathering resistance should be taken into account to gain more knowledge about the behavior of the bond in long term application.

\section{Induction Welding}

Induction heating is caused by alternating electromagnetic fields that transfer electric energy from an induction coil into an electro conductive material without physical contact. An alternating electromagnetic field occurs around an induction coil when a high-frequency alternating current passes through it. If an electric conductor is brought into the electromagnetic alternating field, heat is generated in the electrical conductor as a result of resistance and hysteresis losses. $[4,5,6]$

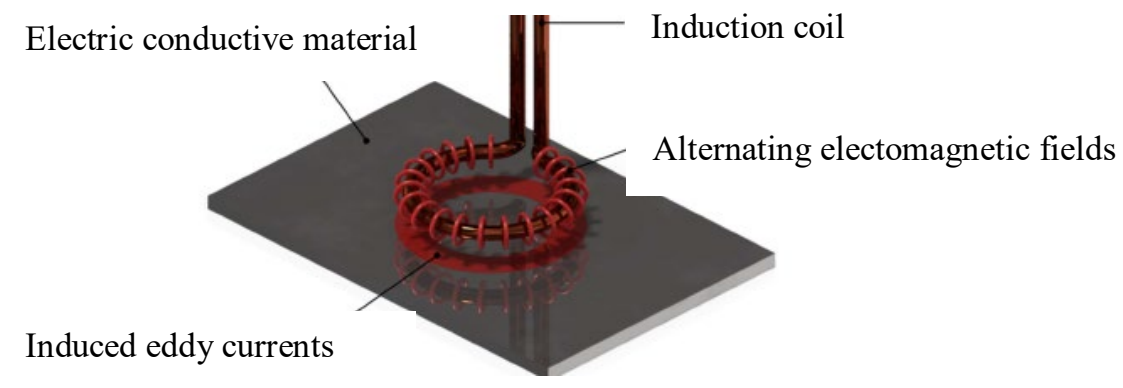

Figure 1: Induction heating of electric conductive material 
The resistance losses increase quadratically with increasing frequency of the alternating field and are the main reason of heat generation in both, non-magnetic and ferromagnetic materials. If the electrical conductive material is ferromagnetic, additional heat is generated by magnetic hysteresis losses. In contrast to the resistance losses, this heat generation is of less importance, since hysteresis losses increase linearly with frequency. The hysteresis losses are caused by the alternating electromagnetic field, which generates heat due to friction generated by a change in direction of the magnetic dipoles of the ferromagnetic material. [7, 8]

\section{Hybrid Joining Techniques}

In literature various hybrid joining processes dealing with joining metals to TP-FRPC are reported and tensile shear strengths are stated. Jung et al. [9] investigated the bond strength of degreased welded to carbon fiber reinforced polyamide by laser direct joining. The achieved bond strength is $15 \mathrm{MPa}$. Velthuis et al. [10] investigated induction-welded hybrid joints. The material combination was AlMg3 with carbon fiber reinforced polyamide $66(13.5 \mathrm{MPa})$ and 1.0330 with carbon fiber reinforced polyetherether ketone $(18 \mathrm{MPa})$. Both metals were surface pretreated by compressed air blasting and the TP-FRPCs were plasma pretreated. Hümbert et al. [5] used induction welding to join 1.0330 with glass fiber reinforced polyamide 6 (GF-PA6). The surface pretreatment was carried out by laser structuring; the achieved bond strength is $19 \mathrm{MPa}$. Scheick et al. [11] used thermal direct joining to join 1.4301 respectively Al 3.3457 with GF-PA6. In this study GF-PA6 was plasma pretreated. The bond strength achieved for both material combinations was approx. $10 \mathrm{MPa}$. Klotzbach et al. [12] used heating elements to join compressed air pre-treated steel with an adhesion agent coating to GF-PA6. The achieved bond strength is $30 \mathrm{MPa}$. However, all mentioned studies did not consider the weathering resistance of the hybrid structures. Amend et al. [13] used mono- and polychromatic radiation to join cross- and crater-structured aluminum (AW5182) with GF-Polycarbonate (GF-PC), GF-PA6 and GF-PA66. The bond strength achieved was 19.7 MPa for AW-5182 with GF-PC, 16.3 MPa for AW-5182 with GF-PA6 and 20.8 MPa for AW5182 with GF-PA66. In addition, Amend et al. conducted climatic tests with the joined specimens, the strength decreased by a quarter for GF-PC/AW-5182 and a half for PA66/ AW-5182 and PA6/ AW-5182 compared to the initial strength. Didi et al. [2] determined the joint strength on compressed air-blasted or nitric acid etched AA5754 welded by induction to carbon fiber reinforced PA66. The maximum bond strength is $14.2 \mathrm{MPa}$. Furthermore the welded samples were exposed to natural weathering for 6,9 respectively 12 months and afterwards tested by lap shear tests. In [2], it is shown that pressured air blasted and untreated AA5754 specimens offer only a poor bonding quality after weathering. Additionally it is shown that acid etching of the surface lead to an improvement in weathering resistance.

\section{Materials and Surface Treatments}

The metal plates were laser-structured mild steel or a bonding agent surface-coated mild steel respectively. The laser structuring in line pattern perpendicular to the load direction was generated by a water cooled IPG $1000 \mathrm{~W}$ single-mode fiber laser. The focusing optics has a focal length of $330 \mathrm{~mm}$, the resulting spot has a radius of $20 \mu \mathrm{m}$. The 1.0330 sheets were coated with a bonding agent in accordance to the product specific application procedures. A characterization of the surface pretreated mild steels is shown in Table 1 
Table 1: Characterization of surface pretreated mild steel

\begin{tabular}{|c|c|c|}
\hline Acronym & LS_1.0338 & \begin{tabular}{l|l} 
Köratac & Köratac \\
HL400_1.0330 & HL403 1.0330
\end{tabular} \\
\hline Surface pretreatment & $\begin{array}{l}\text { Laserstructuring, } \\
\text { Structuring distance } 0.3 \mathrm{~mm}\end{array}$ & $\begin{array}{l}\text { Bonding agent Köratac HL } 400 \& \text { Köratac } \\
\text { HL } 403 \text {; optimized for polypropylene; } \\
\text { coating thickness approx.: } 10 \mu \mathrm{m}\end{array}$ \\
\hline Material number & 1.0338 & 1.0330 \\
\hline Sheet thickness & $1 \mathrm{~mm}$ & $1 \mathrm{~mm}$ \\
\hline $\begin{array}{l}\text { Visualization of } \\
\text { surface pre-treatment }\end{array}$ & $\begin{array}{l}\text { Ra: } 35.51 \pm 1.7 \mu \mathrm{m} ; \\
\text { Rz: } 235.5 \pm 13.4 \mu \mathrm{m}\end{array}$ & \\
\hline Micrograph & TP-FRPC & Köratac HL400_1.0330 \\
\hline $\begin{array}{l}\text { Sketch of pre- } \\
\text { treatments on } \\
\text { specimen surface }\end{array}$ & $\underset{\text { Laser structuring }}{\langle\text { Load direction }}$ & 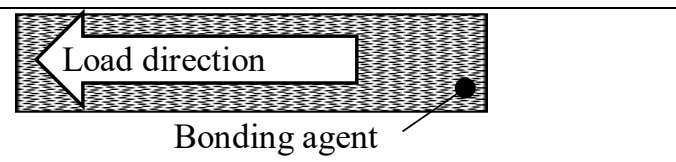 \\
\hline $\begin{array}{l}\text { Adhesion } \\
\text { mechanisms between } \\
\text { joining partners }\end{array}$ & $\begin{array}{l}\text { Positive between TP-FRPC and mild } \\
\text { steel }\end{array}$ & Physically binding \\
\hline Annotations & $\begin{array}{l}\text { Steel sheet was galvanized before } \\
\text { laser structuring }\end{array}$ & $\begin{array}{l}\text { Metal sheets are usually coated by coil } \\
\text { coating processes }\end{array}$ \\
\hline
\end{tabular}

Glass fiber reinforced -polyamide 6 (PA6), -polypropylene (PP), -polycarbonate (PC) and polyphenylene-sulfide (PPS) were used as TP-FRPC joining partner. The fiber reinforcement was glass fiber fabric (twill 2/2) with an area weight of $600 \mathrm{~g} / \mathrm{m}^{2}$. The laminates were made of four layers fabric resulting in a laminate thickness of $2 \mathrm{~mm}$. The fiber volume content was $47 \%$ for all TP-FRPC. A detailed characterization of the TP-FRPC is shown in Table 2.

Table 2:Used TP-FRPC

\begin{tabular}{|c|l|l|l|}
\hline Acronym & Matrix polymer & Melting temperature & Material identification \\
\hline GF-PA6 & Polyamide 6 & $220^{\circ} \mathrm{C}$ & Bond-Laminates - Tepex dynalite 102 RG 600 \\
\hline GF-PP & Polypropylene & $163^{\circ} \mathrm{C}$ & Bond-Laminates - Tepex dynalite 104 RG 600 \\
\hline GF-PC & Polycarbonate & $\begin{array}{l}\text { Processing temperature } \\
220^{\circ} \mathrm{C}\end{array}$ & $\begin{array}{l}\text { IVW GmbH } \\
\text { Matrix polymer: Bayer - Makrofol DE6-2 } \\
\text { Fabric: OCV Technical Fabrics }\end{array}$ \\
\hline GF-PPS & Polyphenylene-sulfide & $280{ }^{\circ} \mathrm{C}$ & $\begin{array}{l}\text { IVW GmbH } \\
\text { Matrix polymer: Manufacturer unknown } \\
\text { Fabric: OCV Technical Fabrics }\end{array}$ \\
\hline
\end{tabular}

\section{Experimental Set-Up and Test Execution}

The lap shear specimens according to DIN 1465 were welded on a discontinuous induction welding test rig shown on the left hand side of Figure 2. The test rig consists of a pneumatic press with a consolidation stamp with integrated induction coil. The induction coil used is a circular 
pancake induction coil with a diameter of $35 \mathrm{~mm}$ located $5 \mathrm{~mm}$ above the coil facing surface of the metallic joining partner. A consolidation plate made of ceramic which is permeable to the electromagnetic fields is placed between the metal sample and the induction coil in order to guarantee an efficient heating without energy losses. As induction inverter a TrueHeat HF 5010 by TRUMPF is used. The lap shear test specimens were positioned horizontally on an aluminum positioning tool and below the consolidation stamp. [3]

Before welding, degreasing of the TP-FRPC and laser-structured steel joining partners was carried out using isopropanol. The steel joining partners coated with bonding agents were wiped dry to avoid the isopropanol from affecting the coating. A thermocouple (type K) was placed in the joining zone to measure the temperature during welding and remains in the joining zone after welding. When welding lap shear specimen, first, the joining partners are positioned on the aluminum tool, then the consolidation stamp moves onto the joining partners and applies the joining force. When the constant force is applied, the induction coil gets passed by the alternating current generated by the inverter and thus the metal sample is heated by induced eddy currents. During process, the temperature in the joining zone, the consolidation force and the inverter current are supervised. The temperature in the joining zone is used to control the process and was kept constant at the target welding temperature for $10 \mathrm{~s}$. After heating, a compressed air cooling unit was used to cool the joining partners with an air flow rate of $90 \mathrm{l} / \mathrm{min}$. Six lap shear specimen were welded for each parameter set. The bond strength of five specimens was determined by tensile shear tests and the remaining specimen was used to create a micrograph. The tensile shear tests were conducted according to DIN EN 1465 on a universal testing machine (Zwick 1474). The testing force was measured on the traverse by a $100 \mathrm{kN}$ load cell, the free test length was $112.5 \mathrm{~mm}$, the test velocity was $1 \mathrm{~mm} / \mathrm{min}$. The experimental set-up for tensile shear test and lap shear specimen geometry is shown schematically on the right hand side of Figure 2.
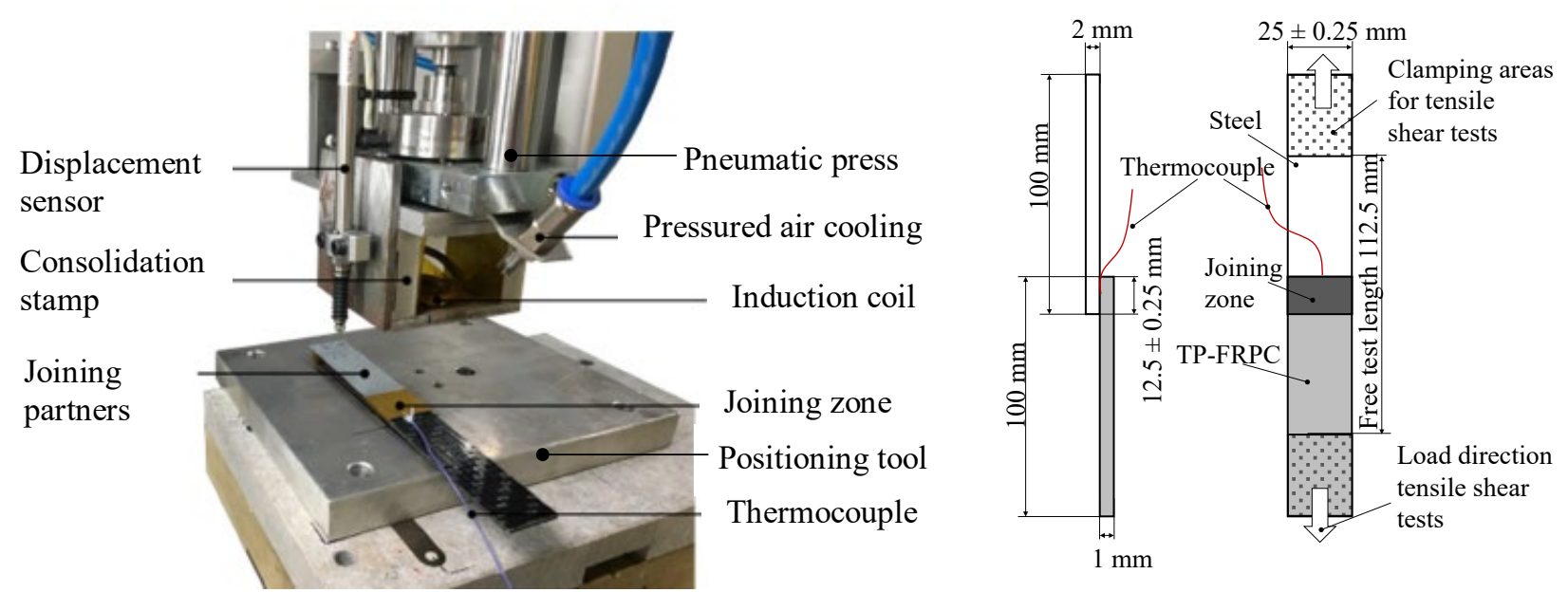

Figure 2: Left: discontinuous induction welding test rig; right: dimensions of lap shear specimen and experimental set up of tensile shear tests

In the first part of the study, the influence of welding temperature on bond strength was considered. The welding parameter force and inverter current were kept constant. The joining partners were welded at three different welding temperatures. The lower temperatures were $10^{\circ} \mathrm{C}$ above melting temperature of matrix polymer, the higher temperature $50{ }^{\circ} \mathrm{C}$ above melting temperature and one temperature was chosen between. In the case of metal sheets coated with bonding agents joined to GF-PPS, only one temperature of $300{ }^{\circ} \mathrm{C}$ was investigated, since this temperature is above the degradation temperature of the bonding agent. A further increase in temperature would result in an ongoing decomposition of the bonding agent and thus damage the bond mechanisms leading to a decrease in bond strength.

In the second part of the study, lap shear test specimens were welded according to DIN 1465 using the welding temperature with the highest bond strength was achieved in the first part of the study. Then the influence of two weathering tests on bond strength was investigated. The weathering tests carried out were an industry standard climate change test (BMW PR 308.2) and a cataplasma test (DIN EN ISO 9142). 


\section{Climate change test according to BMW PR 308.2}

Climate change test according to BMW PR 308.2 allows to investigate influences of moisture, warm humidity, oxidation-promoting conditions and freezing water on bond strength. In addition, the influence of different thermal expansions of the used materials on bond strength can be considered. On the left side of Figure 3, the temperature and humidity graphs of one weathering cycle according to BMW PR 308.2 are shown; the lap shear specimens were exposed to a total of ten cycles.

\section{Cataplasma test according to DIN EN ISO 9142}

Performing cataplasma test according to DIN EN ISO 9142, first, the lap shear specimens are wrapped in water-soaked cotton wool; hermetically sealed in an aluminum/PE composite foil. Then the sealed lap shear specimens were stored at $70 \pm 2{ }^{\circ} \mathrm{C}$ for seven days and afterwards in a freezer at $-20 \pm 2{ }^{\circ} \mathrm{C}$ for 15 hours. After this procedure, the samples were removed out of the foil and reconditioned for 24 hours at room temperature. On the right part of Figure 3, the temperature profile over the storage time of the lap shear specimens is shown.

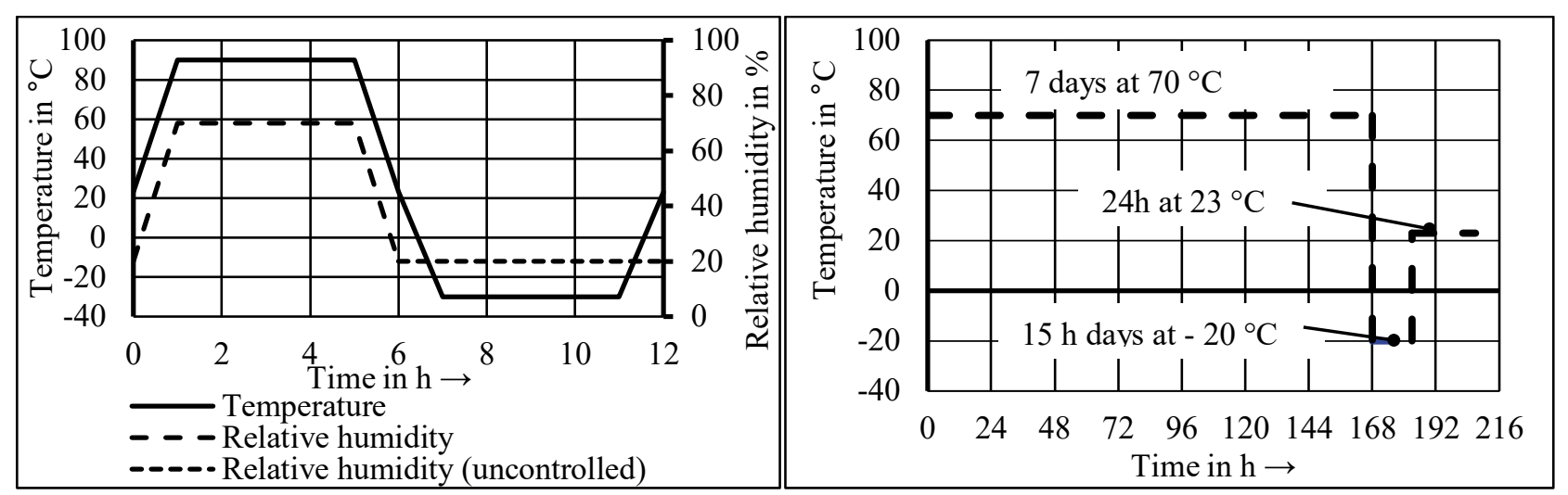

Figure 3: Left: Climatic change test according to BMW PR308.2; right: cataplasma test accoring to DIN EN ISO 9142

\section{Results and Discussion}

Influence of welding temperature on bond strength

In order to evaluate the influence of welding temperature on bond strength, three different welding temperatures for LS_1.0338 welded to TP-FRPC mentioned in Table 2 were investigated. The results and welding parameters are shown in Figure 4.

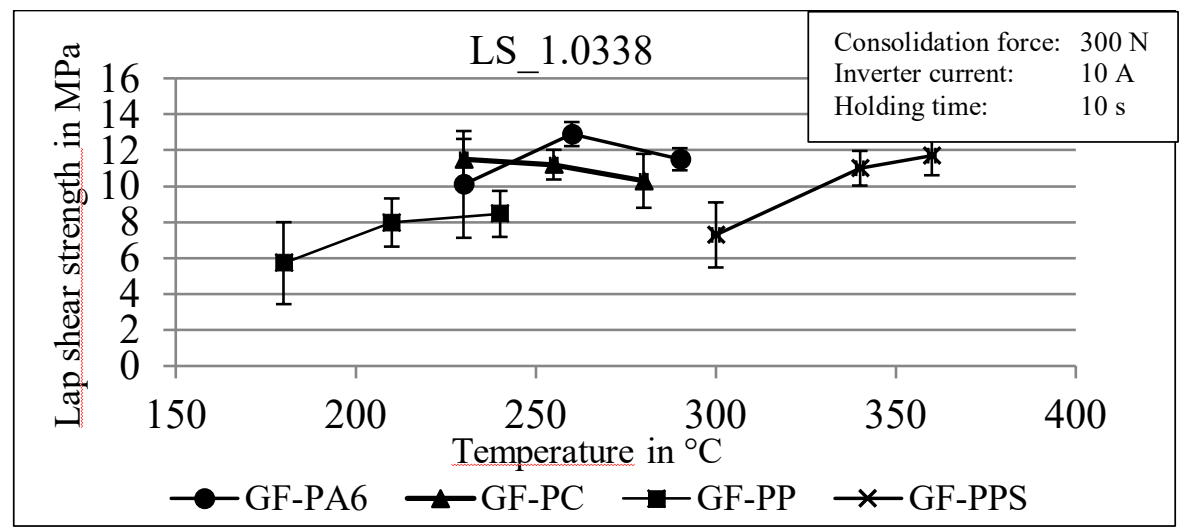

Figure 4: Influence of welding temperature on bond strength of $L S$ _1.0338 welded to various TP-FRPC

It is evident that the optimum welding temperatures depend on the material combination. The highest bond strength was achieved for GF-PA6 at $260{ }^{\circ} \mathrm{C}$ with $12.9 \mathrm{MPa}$, higher and lower temperatures lead to a decrease in bond strength. GF-PC welded to LS_1.0338 achieves the highest bond strength at $230{ }^{\circ} \mathrm{C}$ with $11.5 \mathrm{MPa}$, higher temperatures lead to a decrease in bond strength. This is in contrast to the other welds and may be affected by the amorphous polycarbonate matrix- 
polymer. Further investigations must be carried out to prove whether this behavior occur at all amorphous thermoplastics. GF-PP welded to LS_1.0338 achieves the highest bond strength at $240{ }^{\circ} \mathrm{C}$ with $8.46 \mathrm{MPa}$. Lower temperatures lead to a drop in bond strength. GF-PPS welded to LS_1.0338 achieves the highest bond strength at $360^{\circ} \mathrm{C}$ with $11.7 \mathrm{MPa}$. Lower temperatures lead to lower bond strength, this behavior is comparable to the results of GF-PP welded to 1.0338.

In order to evaluate the influence of welding temperature on bond strength, three different temperatures for Köratac HL400_1.0330 as well as Köratac HL403_1.0330 welded to the TP-FRPC as reported in Table 2 were investigated. The results and welding parameters are summarized in Figure 5.
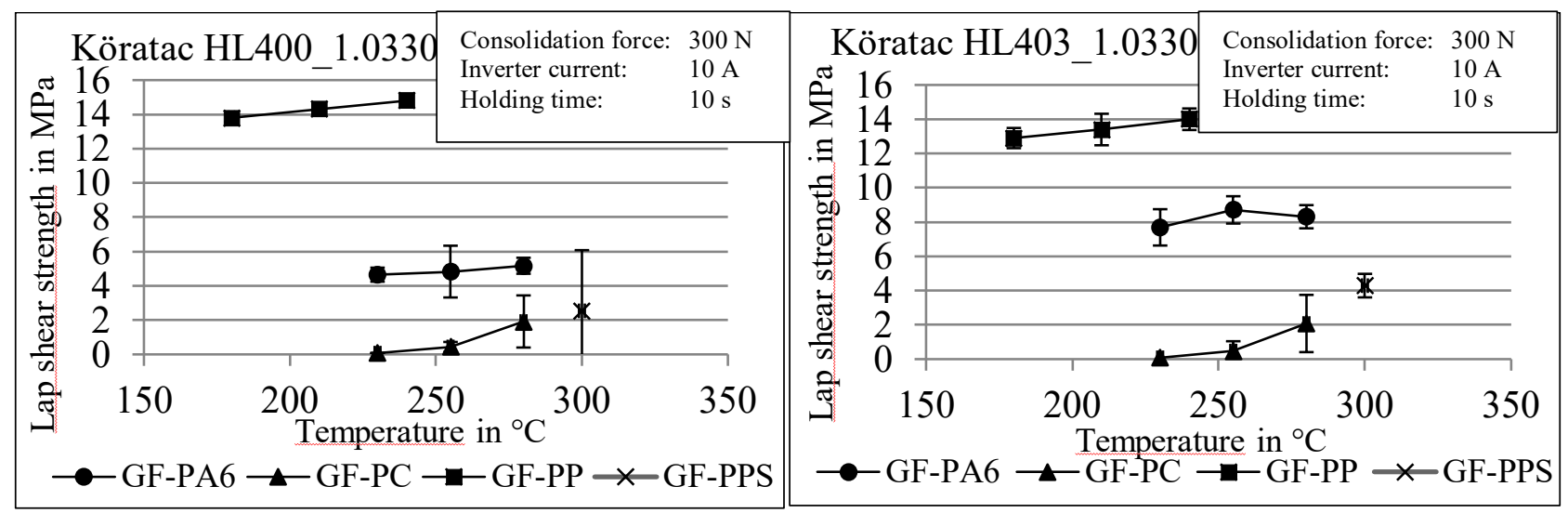

Figure 5: Influence of welding temperature on bond strength of various TP-FRPC welded to Köratac HL400_1.0330 and Köratac HL403_1.0330

There is an optimum welding temperature depending on the material combination. The highest bond strength was achieved for GF-PA6 welded to Köratac HL400_1.0330 at $280{ }^{\circ} \mathrm{C}$ with 5.17 MPa and $260{ }^{\circ} \mathrm{C}$ with $8.71 \mathrm{MPa}$ for Köratac HL403_1.0330. GF-PC welded to both bonding agent coated steel sheets achieved the highest bond strength at $280{ }^{\circ} \mathrm{C}$ with approx. $2 \mathrm{MPa}$. The overall highest bond strength was achieved by GF-PP welded to adhesive agent coated steel at 240 ${ }^{\circ} \mathrm{C}$ with approx. $14 \mathrm{MPa}$, for both functional coatings. The hybrid bonds made of GF-PPS and steel achieve the highest bond strength at $300{ }^{\circ} \mathrm{C}$ with $2.52 \mathrm{MPa}$ for Köratac HL400_1.0330 and 4.29 MPa for Köratac HL403_1.0330. Only one temperature was considered as already explained. Almost all material combinations show an increase in bond strength with increasing welding temperature. Merely the material combination of Köratac HL403_1.0330 and GF-PA6 show a decrease in bond strength from $260{ }^{\circ} \mathrm{C}$ onward. As expected the material combination of Köratac HL400_1.0330 as well as Köratac HL403_1.0330 and GF-PP has higher bond strength than the other hybrid joints. The material combinations metal to GF-PC or GF-PPS respectively were not subjected to weathering because their joint strengths were very low, so it was assumed that the bonding agents are incompatible with these TP-FRPCs.

\section{Influence of weathering on bond strength}

In order to evaluate the influence of the climatic change and cataplasma test on bond strength, after weathering the lap shear specimen were tested the same way as described above. The results of LS.1.0338 welded to the TP-FRPC mentioned in Table 2 are summarized in Figure 6. 


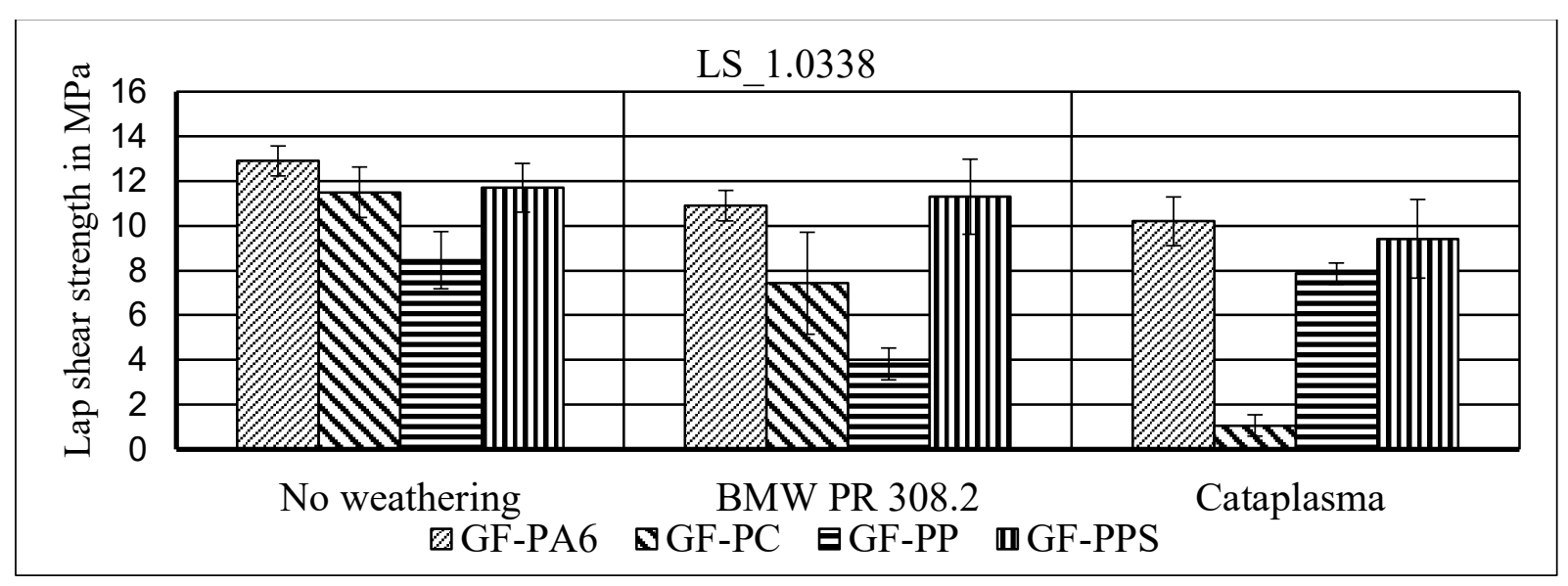

Figure 6: Influence of climatic change and cataplasma test on bond strength

It was found that the bond strength of the hybrid joints was influenced differently depending on the weathering procedure and material combination. For hybrid joints made of LS_1.0338 and GF-PA6, GF-PC and GF-PPS, the cataplasma test has the biggest influence on bond strength. LS_1.0338 welded to GF-PP was mostly influenced by BMW PR 308.3.

Bond strength of Köratac HL400_1.0330 and Köratac HL403_1.0330 welded to GF-PA6 and GF-PP are summarized in Figure 7

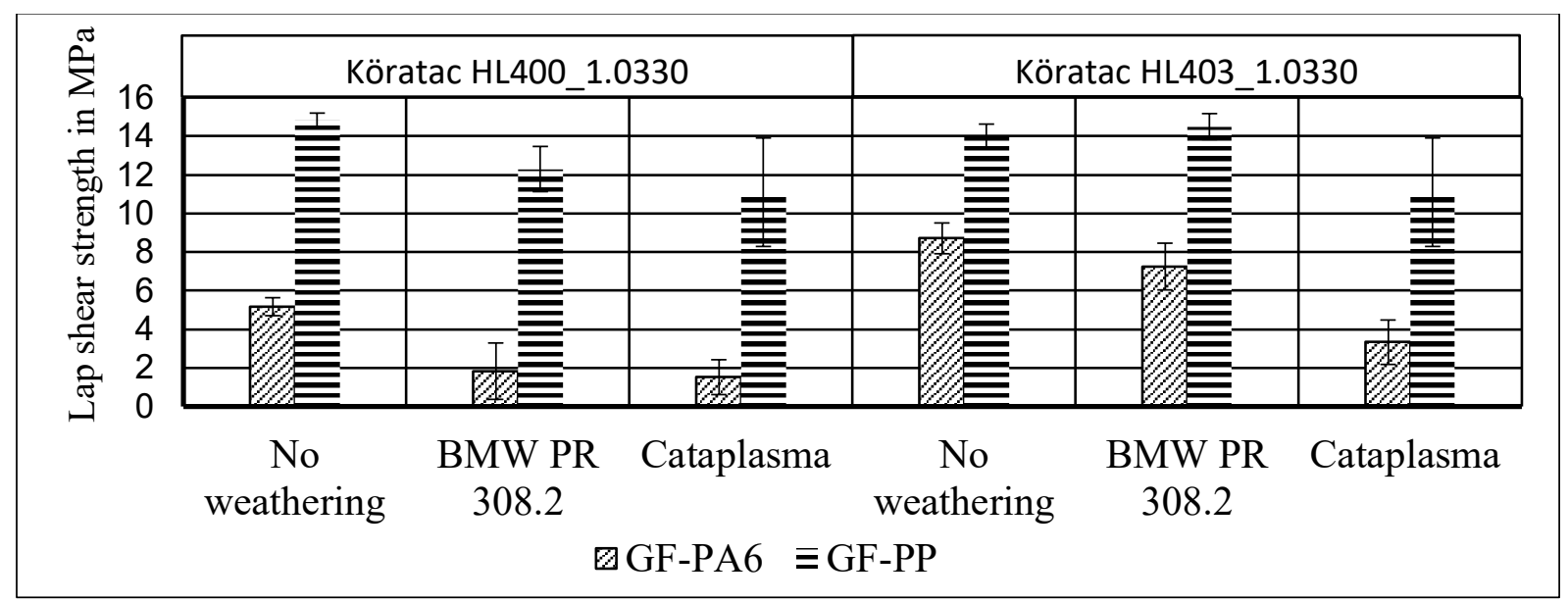

Figure 7: Influence of weathering on bond strength of bonding agent coated steel sheets welded to GF-PA6 or GF-PP

The bond strength of the hybrid joints is influenced differently depending on the weathering procedure and material combination. For hybrid joints made of Köratac HL400_1.0330 and GFPA6 respectively GF-PP and Köratac HL400_1.0330 welded to GF-PA6 respectively GF-PP, the cataplasma procedure has the biggest influence on bond strength. The bond strength of Köratac HL403_1.0330 welded to GF-PP was not influenced by BMW PR 308.2, thus show a good weathering resistance.

\section{Summary}

The temperature obtaining the highest bond strength depends primarily on the matrix polymer of the TP-FRPC. In the case of the material combination of semi-crystalline thermoplastics and laser-structured steel, it can be seen that higher welding temperatures lead to higher bond strengths. In the case of amorphous polycarbonate as matrix polymer, it was shown that a temperature close to the processing temperature was sufficient to achieve the highest bond strengths.

The bonding promoters showed that they are particularly suitable for TP-FRPC with a polypropylene matrix. Moderate joint strengths are achieved with polyamide 6 as matrix polymer, poor joint strengths with polycarbonate and PPS. Steel sheets coated with a bonding agent show also that higher temperatures lead to higher bond strengths. 
Considering the weather resistance of the hybrid joints, it can be seen that the surface pretreatments are differently suitable depending on the material combination. For example, hybrid composites of LS_1.0338 and GF-PA6 are barely affected by weathering. Due to the not optimized bonding agent, bond strength of Köratac HL400_1.0330 and Köratac HL403_1.0330 with GF-PA6 decreases significantly after weathering.

\section{Acknowledgments}

This study has been conducted in the frame of the research project "FlexHyJoin", funded by the Horizon 2020 Research and Innovation Programme of the European Union, funding Code No. 677625.

We want to thank Kömmerling Chemische Fabrik GmbH for coating the steel sheets with bonding agents and weathering the lap shear specimens.

\section{References}

[1] P. Mitschang, R. Velthuis und M. Didi, „Induction Spot Welding of Metal/CFRPC Hybrid Joints," Advanced Engineering Materials. Vol. 15, pp. 804-813, 2013.

[2] M. Didi, S. Emrich, P. Mitschang, Kopnarski und M., „Characterization of Long-Term Durability of Induction Welded Aluminum/Carbon Fiber Reinforced Polymer-Joints, “ Advanced Engineering Materials, pp. 821 - 829, 19 August 2013.

[3] P. Mitschang und S. Weidmann, „Influence of penetration depth on lap shear strength of induction welded steel/TP-FRPC joints, “ ECCM18 - 18th European Conference on Composite Materials, 2018.

[4] S. Becker und P. Mitschang, „Influence of Textile Parameters on the Induction Heating Behaviour of CFRPC, “21st. International Conference on Composite Materials, 2017.

[5] M. Hümbert, Induktiver Schweißprozess für glasfaserverstärkte Thermoplaste und Stahl, Kaiserslautern: IVW Schriftreihe, 2017.

[6] V. Rudnev, D. Loveless, R. L. Cook und B. M., Handbook of Induction Heating, Taylor \& Francis, 2002.

[7] G. Benkowsky, Induktionserwärmung: Härten, Glühen, Schmelzen, Löten, Schweißen ; Grundlagen und praktische Anleitungen für Induktionserwärmungsverfahren, insbesondere auf dem Gebiet der Hochfrequenzerwärmung, Berlin: Technik, 1990.

[8] S. Zinn und S. L. Semiatin, Elements of induction heating: Design, control, and applications, Ohio: ASM Interantional, 2010.

[9] K. Jung, Y. Kawahito und S. Katayama, „Laser Direct Joining of CFRP to Metal or Engineering Plastic,“ Transactions of JWRI, pp. 5-8, 2013.

[10] R. Velthuis, Induction welding of fiber reinforced thermoplastic polymer composites to metals, Kaiserslautern: IVW Schriftreihe, 2007.

[11] S. Scheik, M. Schleser und U. Reisgen, „Thermisches Direktfügen von Metall und Kunststoff Eine Alternative zur Klebtechnik?," in Leichtbau-Technologien im Automobilbau, Wiesbaden, Springer Vieweg, 2014, pp. 89-94.

[12] A. Klotzbach, M. Langer, R. Pautzsch, J. Standfuß und E. Beyer, „Thermal direct joining of metal to fiber reinforced thermoplastic components, " Journal of Laser Applications, Bd. 29, Nr. 2, pp. 362-369, 2017.

[13] P. Amend, S. Pfindel und M. Schmidt, „Thermal Joining of Thermoplastic Metal Hybrids by Means Of Mono- and Polychromatic Radiation,“ Physics Procedia, Nr. 41, pp. 98-105, 2013. 